emphasizes the importance of vaccination, especially in infants and young children.

\section{CLINICAL, ECONOMIC AND HUMANISTIC IMPACT OF SHORT BOWEL SYNDROME - INTESTINAL FAILURE IN PORTUGUESE PAEDIATRIC PATIENTS (PARENTERAL STUDY)}

Raúl Barbosa da Silva, Sara Nóbrega, Paula Guerra, Ricardo Ferreira, Diogo Ramos*, Valeska Andreozzi, Marisa D Santos. Exigo Consultores

\subsection{6/archdischild-2021-europaediatrics.259}

Short Bowel Syndrome - Intestinal Failure (SBS-IF) is a rare, chronic, and debilitating disease, requiring patient-tailored complex management and comprehensive care. Parenteral nutrition (PN) remains the standard-of-care due to its life-sustaining nature. This study aimed to assess the clinical, economic and humanistic impact of paediatric SBS-IF in Portugal.

This was a retrospective cohort study, with a cross-sectional component for the quality of life (QoL) evaluation, including paediatric SBS-IF patients

( $\geq 1$-18 years) with stable PN over at least six months. Data collection included patient chart review over a 12-month period and patient/caregiver self-report and PedsQL ${ }^{\mathrm{TM}}$ questionnaires with 6- and 1-month recall periods, respectively. Main endpoints included clinical and PN characterization, healthcare resource utilization (HRU), direct medical and non-medical costs, and patient QoL. Unit costs were obtained from national databases/decrees, retailers, and patient/caregiver. Costs were standardized using the 2019 consumer price index and annualized assuming constant use of resources.

A total of 20 patients were included with a mean age (SD) of $7.5(5.0)$ years, $50.0 \%$ female, and a mean time since diagnosis of 6.6 (4.2) years. The three leading causes of SBS-IF were volvulus (40.0\%), intestinal atresia $(35.0 \%)$, and necrotizing enterocolitis (10.0\%). PN was administered for a mean of 6.6 days/week, in $90.0 \%$ of cases at home for a mean of 10.8 months/year. Nevertheless, $60.0 \%$ had PN administered at least once in an inpatient setting for a mean of 1.8 months/ year. HRU was high, including a mean annual frequency of 10.2 (5.3) medical visits, 29.8 (85.3) visits with other healthcare professionals (including nurse, dietitian, psychologist),

3.0 (2.5) emergency visits, and 2.0 (1.5) hospitalisations. A total of 40 hospitalizations were reported, with a mean annual length of stay of 29.4

(32.3) days, of which $85.0 \%$ due to catheter-related complications, including septicaemia, local central venous catheter infection, and mechanical complications. Mean annual direct costs $(95 \% \mathrm{CI})$ per patient amounted to $74,734.5 €(74,614.8$ $74,854.4)$, with PN and hospitalization as the main cost drivers accounting for $57.3 \%$ and $21.0 \%$ of overall costs, respectively.

Patient QoL assessment showed a PedsQL ${ }^{\mathrm{TM}}$ mean total score slightly below the Portuguese norm (73.3 vs. 75.6 ), but with a notorious deterioration in the school functioning domain (57.5 vs. 72.6).

Paediatric SBS-IF management is characterized by a substantial therapeutic burden and HRU, translating into high direct costs and QoL deterioration, mainly in school performance. There is a clear unmet need for therapeutic alternatives that lower SBS-IF burden. This research was funded by Takeda.

\section{0 CLUSTER BREASTFEEDING SYNDROME IN INFANTS}

Olga Gumeniuk*, Gumeniuk Olga, Nikolaeva Nataliia, Chernenkov Yuriy. Saratov State Medical University

10.1136/archdischild-2021-europaediatrics. 260

Cluster breastfeeding syndrome («cluster feedings», «bunch feedings") is when baby has several feedings close together during a certain period of time, in some cases during the day. The purpose of this study is to examine the frequency and to identify the reasons for the cluster breastfeeding syndrome in lactating women.

Questioning was conducted with 223 lactating women aged 19-44 years.

Questioning including questions regarding the use of the delivery methods and the lactation period. Psychological testing of lactating women was also conducted. The anxiety level was evaluated by Hamilton Anxiety Rating Scale

(HAM-A) (score of 14 points is borderline). Lactating women were divided into two groups: without Cluster Breastfeeding syndrome (group I) and with Cluster Breastfeeding syndrome (control group). Statistical analysis was performed using Microsoft Excel 2007, SPSS Statistics v 24.0.0.0. Spearman's correlation coefficient ( $r$ ) and Pearson's correlation coefficient (rxy) were calculated. Data was compared using chisquare test and $\mathrm{P} \leq 0.05$ was regarded as statistically significant.

Among the women surveyed, women with one child prevailed (63\%). The average duration of the lactation period was $11.1 \pm 5$ months. The average time the baby was at the breast was $19 \pm 4.1$ minutes. Syndrome of prolonged, continuous feeding was noted in $5 \%$ of cases when the baby was at the chest continuously for a day, with short breaks at night sleep. In this group, in women (90\%), labor was performed by Caesarean section. In the group I (cluster breastfeeding syndrome group), the average age of women was $35.8 \pm$

5.5 years, in the control group $25.0 \pm 4.6$ ( $\mathrm{p}<0.001$ ). In group I, the average score on the Hamilton scale was $28.4 \pm$ 6.5 (level of symptomatic anxiety), in the control group $12.9 \pm 9.7(p=0.0003)$. All baby in the group I have been gaining enough weight and producing sufficient dirty and wet diapers. Correlation analysis revealed a direct strong correlation between the presence of cluster breastfeeding syndrome in a child born by Caesarean section $(r x y=0.97)$ from mothers who gave birth over the age of 35 and have a level of symptomatic anxiety ( $\mathrm{r}=1)$.

Cluster breastfeeding syndrome (cluster feedings, bunch feedings) occurs in 5\% of cases and is associated with the late birth of the first child, high anxiety of the mother and the birth of a child by Caesarean section.

\section{INFANT HEMATEMESIS: A CHALLENGING DIAGNOSIS, POSTNATAL CMV INFECTION OR NON IGE-MEDIATED COW'S MILK PROTEIN ALLERGY? A TWO CASE REPORT COMPARISON}

Mara Fumagalli*, Laura Gianolio, Vania Giacomet, Gian Vincenzo Zuccotti. Department of Pediatric Infectious Diseases, Sacco Hospital, University of Milan, Italy

10.1136/archdischild-2021-europaediatrics.261

Introduction While severe manifestations of congenital Cytomegalovirus (CMV) transmission are widely investigated, little 